\title{
Changes in implicit wanting and explicit liking and wanting for food after gastric bypass surgery
}

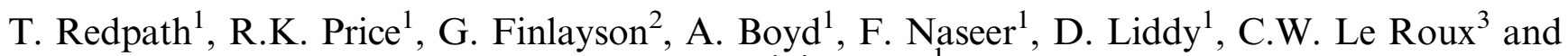 \\ M.B.E Livingstone ${ }^{1}$ \\ ${ }^{1}$ Nutrition Innovation Centre for Food and Health (NICHE), Ulster University, Coleraine, BT52 1SA, ${ }^{2}$ Institute of \\ Psychological Sciences, University of Leeds, West Yorkshire, LS2 9JT and ${ }^{3}$ Diabetes Complications Research Centre, \\ University College Dublin, Ireland.
}

Gastric bypass surgery (GB) is a safe, effective treatment for morbid obesity ${ }^{(1)}$. Aside from reduced energy consumption, patients report changes in food preferences and appetite that may contribute to weight loss post-surgery ${ }^{(2,3)}$. Food preferences can be separated into two constructs; 'liking' (pleasure) and 'wanting' (motivation/desire to eat) ${ }^{(4)}$ which may be influenced by physiological and psychological changes post-surgery. The aim of this study was to investigate changes in food preferences ('liking' and 'wanting') in GB patients from pre- to post-surgery, compared to weight-stable controls.

Nineteen patients $\left(45 \cdot 2 \pm 12.5\right.$ years, Body Mass Index (BMI): $\left.45 \cdot 3 \pm 6.4 \mathrm{~kg} / \mathrm{m}^{2}\right)$ and sixteen time-matched controls $(44.7 \pm 15 \cdot 6$ years, BMI: $25 \pm 4.4 \mathrm{~kg} / \mathrm{m}^{2}$ ) completed the computer-based Leeds Food Preference Questionnaire, which assesses preferences for sweet/savoury foods and low-fat/high-fat foods ${ }^{(5)}$, at baseline (1-month pre-surgery) and 3-months post-surgery. Explicit liking and wanting (conscious hedonic feelings/desire to consume) were measured using Visual Analogue Scales, whilst implicit wanting (unconscious motivational expression) was measured using food selection and reaction times in a forced-choice task.

There were no significant differences in food preferences between patients and controls at baseline. BMI for controls remained stable $\left(+0.1 \pm 1.3 \mathrm{~kg} / \mathrm{m}^{2}, \mathrm{p}=0.73\right)$, whilst BMI in patients significantly decreased $\left(-8.3 \pm 2.7 \mathrm{~kg} / \mathrm{m}^{2}, \mathrm{p}=<0 \cdot 01\right)$. GB patients expressed a significant decrease in the explicit liking $(F(1,33)=10 \cdot 42, p=0 \cdot 03)$, explicit wanting $(F(1,33)=5 \cdot 76, p=0.02)$ and implicit wanting $(\mathrm{F}(1,33)=4.92, \mathrm{p}=0.03)$ for sweet foods after surgery. However, there were no significant changes in preferences for high-fat foods in patients from pre to post-surgery. There were no significant changes in preferences for controls for sweet or high-fat foods.

In conclusion, patients express a significant decrease in preferences for sweet foods post-surgery. As changes in implicit unconscious motivational expression of food preferences may be more predictive of actual food consumption ${ }^{(6)}$ these findings highlight a possible mechanism responsible for the success of GB as an obesity treatment.

1. Colquitt JL, Pickett K et al. (2014) Cochrane Database Syst Rev 8, CD003641.

2. Mathes CM \& Spector AC (2012) Physiol Behav 107, 476-483.

3. Miras AD \& Le Roux CW (2013) Nat Rev Gastroenterol Hepatol 10, 575-584.

4. Berridge KC \& Robinson TE (2003) Trends Neurosci 26, 507-513.

5. Finlayson G, King N \& Blundell J (2008) Appetite 50, 120-127.

6. Pool E, Sennwald V et al. (2016) Neurosci Biobehav Rev 63, 124-142. 